Original Research Paper

\title{
Analisis Keperluan Fungsi e-WLOAD
}

\author{
Asma Hanee Ariffin ${ }^{1}$, Rohaizah Abdul Wahid ${ }^{1}$, Marzita Mansor ${ }^{1}$, Suliana Sulaiman ${ }^{1}$ \\ ${ }^{1}$ Universiti Pendidikan Sultan Idris, Malaysia.
}

\section{Article History \\ Received: \\ 15.01 .2021}

Revised:

21.03.2021

Accepted:

11.04.2021

*Corresponding Author:

Asma Hanee Ariffin

Email:

asma@fskik.upsi.edu.my

This is an open access article, licensed under: $\mathrm{CC}-\mathrm{BY}-\mathrm{SA}$
Abstrak: Isu beban tugas berlebihan di kalangan pendidik telah menghasilkan penciptaan e-WLOAD, sistem pengagihan beban tugas pensyarah (pengajaran dan pengurusan) bagi mengatasi masalah ketidak-seimbangan beban tugas dan kepakaran dalam organisasi. Walaupun terdapat pelbagai sistem dan aplikasi bagi proses pengagihan tugas di pasaran, namun ianya tidak mengkhususkan kepada bidang pendidikan yang melibatkan pelbagai sumber pengetahuan dan proses yang kompleks. Pembentangan ini memfokuskan kepada kejuruteraan keperluan bagi penghasilan keperluan fungsian sistem. Proses yang terlibat adalah elisitasi dan analisis keperluan menggunakan teknik penilaian dokumen dan temubual, membina spesifikasi keperluan dan validasi spesifikasi. Dapatan akhir proses berupaya menggariskan secara terperinci keperluan fungsian sistem dari perspektif proses dan data yang terlibat. Sistem eWLOAD mampu mencadangkan pensyarah yang bersesuaian bagi kursus berdasarkan kriteria bidang kepakaran dan kelayakan, skor kekerapan dan beban kredit pengajaran seterusnya mampu menjana jadual beban tugas pengajaran jabatan yang menitik beratkan keseimbangan beban kredit antara pensyarah dan sela masa semester pengajaran. Sistem juga mampu mencadangkan pensyarah bagi tugas pengurusan sesuai dengan kelayakan, kepakaran dan beban semasa.

Kata Kunci: Beban Tugas, Analisis Keperluan, e-WLOAD.

\section{Needs Analysis for E-WLOAD}

Abstract: The issue of excessive workload among educators has resulted in the creation of e-WLOAD, a lecturer's workload distribution system (teaching and management) to overcome the problem of workload imbalance and expertise in the organization. Although there are various systems and applications for the task distribution process in the market, but it does not specialize in the field of education which involves various sources of knowledge and complex processes. This presentation focuses on engineering requirements for the production of system functional requirements. The process involved is elicitation and needs analysis using document evaluation and interview techniques, constructing specification requirements and validation of specifications. The final findings of the process are able to outline in detail the functional requirements of the system from the perspective of the process and the data involved. The e-WLOAD system is able to recommend suitable lecturers for the course based on criteria of expertise and qualifications, frequency scores and teaching credit load which in turn is able to generate a departmental teaching workload schedule that emphasizes the balance of credit load between lecturers and teaching semester intervals. The system is also able to recommend lecturers for management tasks in accordance with current qualifications, expertise and load.

Keywords: e-WLOAD, Needs Analysis, Workload. 


\section{Pendahuluan}

Pengurusan sebuah institusi amat mencabar dan dengan adanya gelombang transformasi dan juga teknologi telah membawa banyak pembaharuan kepada pengurusan. Penggunaan sistem informasi kemudian menjadi satu keperluan untuk membantu pentadbiran sebuah institusi, seperti dalam bidang kesehatan [1], keuangan [2] [3], industri pembuatan [4] [5] [6] [7]. Demikian juga dengan institusi pendidikan, yang mana sistem informasi direka untuk memudahkan pengurusan sumber manusia, seperti yang dijelaskan dalam Yulianti and Normalisa [8], Herdiyanto and Normalisa [9], Hasbullah and Mohd Noor [10].

Pengurusan sumber manusia bagi sesebuah intstitusi pendidikan boleh didefinasikan sebagai aktiviti kompleks yang perlu dikendalikan secara telus, cekap dan saksama oleh pentadbir. Pengagihan beban tugas pendidik merupakan antara aktiviti terpenting dalam proses tersebut. Aktiviti ini secara signifikannya menentukan keberhasilan matlamat institusi bagi melahirkan pelajar yang berkualiti.

Gelombang transformasi negara dalam industri pendidikan dan juga teknologi telah membawa banyak pembaharuan kepada corak kerja pendidik. Beban tugas seseorang pendidik kini melangkaui skop pengajaran dan memerlukan kepelbagaian sumber bagi perlaksanaannya. Pengagihan beban tugas yang tidak telus dan tidak berlandaskan kriteria tertentu akan menyebabkan ketidakpuashatian antara kakitangan. Tuntutan beban tugas tanpa kawalan akan mengakibatkan keletihan fizikal, gangguan psikologi dan emosi seterusnya meningkatkan stress dan kemurungan. Pengaruh negatif ini akan menurunkan kualiti dan prestasi pencapaian organisasi secara menyeluruh. Bagaimana seorang pelajar yang hebat mampu terlahir dari pendidik yang mati jiwanya? Sebagai langkah pencegahan terhadap masalah tersebut, kajian ini adalah bertujuan untuk mengenalpasti keperluan bagi system eWLOAD untuk pengagihan beban tugas dalam industri pendidikan.

\section{Kajian Literatur}

Pengurusan pengagihan beban tugas adalah proses pembinaan jadual kerja bagi setiap kakitangan dalam organisasi agar matlamat organisasi dapat dicapai secara optimum di mana dalam konteks industri pendidikan fokus utamanya adalah menawarkan perkhidmatan dari sudut pengetahuan dan kemahiran kepada pelajar. Proses ini melibatkan penentuan jumlah kakitangan beserta kepelbagaian sumber atau kriteria (seperti kemahiran, pengetahuan, pengalaman, kekangan peralatan dan mobiliti dan sebagainya) yang diperlukan untuk memenuhi sesuatu beban tugas.

Fleksibiliti kakitangan dan jenis tugasan tersebut juga perlu diambil kira berdasarkan waktu. Pengurusan pengagihan beban tugas secara manual tanpa berpandukan pelan strategik yang komprehensif akan mengakibatkan pengurusan tenaga kerja yang tidak seimbang antara kakitangan dimana terdapat kakitangan yang mempunyai beban kerja melebihi daripada yang sepatutnya dan di sebelah pihak lagi mempunyai beban yang kurang dari sepatutnya dalam suatu tempoh masa tertentu. Ianya mendatangkan konflik rakan sejawat dan tekanan individu dalam organisasi [11].

Kaedah pengagihan yang tidak khusus juga menyebabkan kemahiran dan kepakaran kakitangan juga tidak dapat digunakan secara optimum. Penjadualan kerja yang tidak teratur juga menyebabkan kakitangan yang berkemahiran dalam tugas yang sepatutnya terpaksa menolak atas permintaan yang tidak munasabah mengikut peruntukan waktu dan komitmen terhadap tugas. Kakitangan tidak mempunyai ruang waktu peralihan antara satu tugasan dengan tugasan yang lain. Tidak kurang juga pekerja diberi tugas yang tidak wajar dengan kemampuan dan kemahiran mereka.

Justeru, peningkatan kerjaya dan pembangunan kepakaran seseorang kakitangan sukar dicapai. Elemen-elemen ini memberi impak negatif yang sama besar kepada organisasi mahupun kepada kakitangan itu sendiri. Organisasi tidak mendapat manfaat yang sebenar daripada kakitangan ke arah penghasilan output yang berkualiti disamping kerugian dari sudut kos dan masa. Kesihatan dan keselamatan psikologi pekerja juga akan berada pada tahap membimbangkan. Oleh yang demikian, perlu untuk mewujudkan satu mekanisma yang telus bagi mengatasi permasalahan ini. Ianya boleh dicapai dengan penggunaan sistem berasaskan komputer yang menggunapakai algoritma berasaskan kepintaran buatan [12].

Terdapat beberapa kajian telah dilakukan berkaitan dengan penghasilan sistem bebanan tugas termasuklah sistem agihan bebanan tugas bagi guru. Antaranya Hosain [13], Corry [14] Ambotang dan Bayong [15], yang telah menjalankan kajian terhadap beban tugas di dalam bidang pendidikan. Meski skop responden dan kaedah kajian yang dilakukan adalah berlainan, tetapi kedua-duanya mempersetujui perlu ada satu kaedah beban tugas yang sistematik untuk membantu tenaga pengajar memaksimumkan tenaga dan kepakaran mereka secara kebih meluas. 
Hosain [13] telah menjalankan kajian berkaitan prestasi guru dan beban tugas di beberapa buah universiti di Bangladesh melalui kaedah kuantitatif ke atas seluruh pensyarah di beberapa universiti. Hasil kajiannya menjelaskan keperluan untuk menyusun semula beban tugas pensyarah adalah sangat penting dan perlu diberi penekanan. Kajian beban tugas ini dilihat dapat membantu menghasilkan satu beban tugas yang bersifat lebih relaistik kepada para pensyarah universiti. Dalam kajian yang dilakukan, dapatan menunjukkan terdapat keperluan dalam menyemak beban tugas pensyarah untuk menjana prestasi kerja yang lebih optimum. Manakala Corry [14] dalam kajiannya yang menggunakan pendekatan kualtitatif telah mengemukakan beberapa kaedah formulasi untuk mengira beban tugas secara tersusun. Namun demikian, oleh kerana kedua kajian ini hanya melihat kepada aspek beban tugas dan prestasi dalam skop yang ringkas terdapat keperluan dalam melihat keperluan beban tugas secara lebih spesifik dan menyeluruh.

\section{Metodologi}

Pengumpulan analisis keperluan dilakukan dalam tiga fasa yang berbeza. Fasa pertama adalah elisitasi dan analisis keperluan. Dalam fasa ini teknik seperti analisis dokumen dan temubual telah digunakan untuk melihat keperluan fungsian yang diperlukan oleh e-WLOAD. Garis panduan beban tugas, borang penilaian prestasi (LNPT), buku program kursus dan rekod lampau beban tugas pensyarah dianalisis untuk melihat keperluan beban pensyarah dari segi jam mengajar dan garis panduan yang telah ditetapkan oleh pihak universiti.

Selain itu dokumen klasifikasi pengkomputeran juga dianalisis untuk memastikan pensyarah mengajar subjek yang skopnya agak sama contohnya data structure dan object-oriented programming yang mana kedua-dua subjek ini masih lagi berkaitan dengan bidang pengaturcaraan. Jadi masa yang diambil untuk memahami dan mendalami kedua-dua subjek ini dapat dijimatkan berbanding dengan pensyarah yang perlu mengajar subjek object-oriented programming dan networking.

Teknik temubual juga digunapakai untuk mendapatkan data daripada ketua jabatan dan timbalan pendaftar.

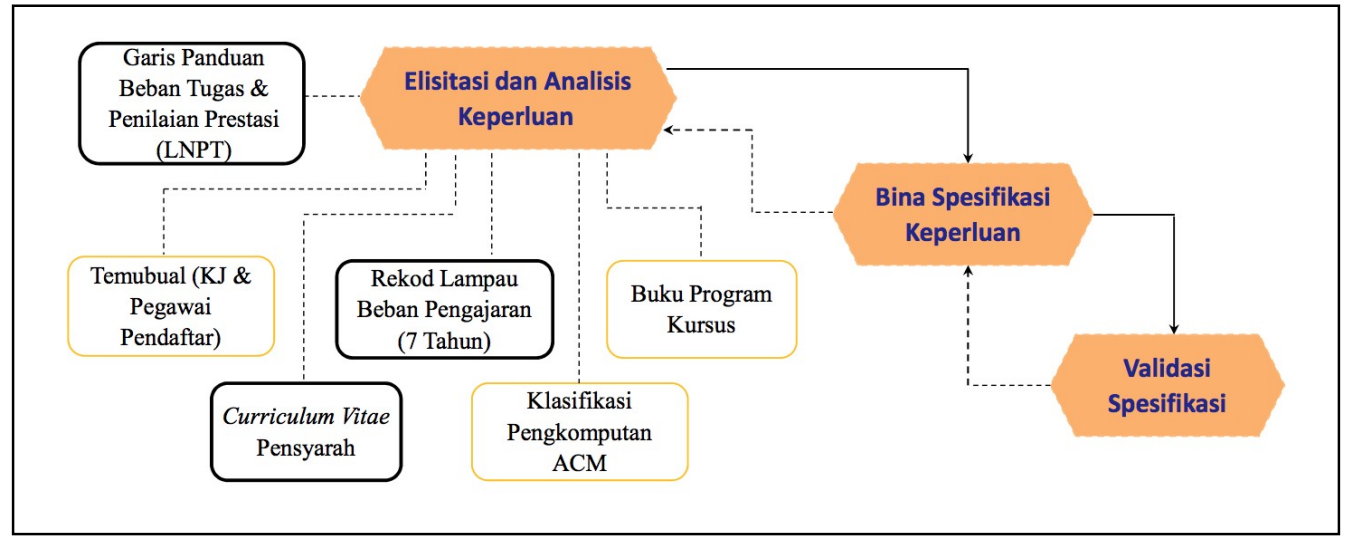

Rajah 1. Metodologi e-WLOAD

Fasa berikutnya adalah fasa membina spesifikasi keperluan. Dalam fasa ini kesemua hasil keperluan fungsian yang didapati dalam fasa satu disenaraikan. Kekangan bagi setiap fungsian juga dikenalpasti. Setiap parameter yang terlibat dengan fungsian juga dikenalpasti

Fasa terakhir adalah fasa validasi spesifikasi. Fasa ini akan memastikan setiap spesifikasi fungsian yang dihasilkan mestilah tepat, lengkap, konsisten dan jelas. Ketiga-tiga fasa ini bersifat iteratif bagi memastikan setiap keperluan fungsian dapat dijana. Rajah 1 menunjukkan metodologi yang digunakan bagi menghasilkan keperluan fungsian e-WLOAD.

\section{Dapatan dan Kesimpulan}

Secara keseluruhan 18 keperluan fungsi yang berkaitan dengan e-WLOAD telah dikenalpasti seperti yang disebutkan dalam Jadual 1. 


\section{Jadual 1. Analisis Keperluan Bagi E-WLOAD}

\begin{tabular}{|c|c|}
\hline Keperluan Sistem & Deskripsi Keperluan \\
\hline $\begin{array}{l}\text { Req 1: } \\
\text { Jana Jadual Beban Tugas }\end{array}$ & $\begin{array}{l}\text { Sistem dapat menjana jadual beban tugas bagi semester yang } \\
\text { ditetapkan }\end{array}$ \\
\hline $\begin{array}{l}\text { Req 1.1: } \\
\text { Pengesahan Input sistem }\end{array}$ & $\begin{array}{l}\text { Sistem dapat mengesahkan senarai kod kursus yang dimasukkan } \\
\text { adalah sah dan tidak bertindan, bilangan kumpulan kuliah } \\
\text { dimasukkan (nilai }>=1 \text { ), serta kod semester bukanlah kod yang lalu } \\
\text { (kod sem }>\text { kod sem semasa). }\end{array}$ \\
\hline $\begin{array}{l}\text { Req 1.2: Penetapan Pensyarah } \\
\text { Bagi Kumpulan kuliah kursus }\end{array}$ & $\begin{array}{l}\text { Sistem dapat menetapkan setiap kumpulan kuliah bagi kursus } \\
\text { ditugaskandengan seorang pensyarah. }\end{array}$ \\
\hline $\begin{array}{l}\text { Req 1.2.1: Penetapan kursus } \\
\text { diberi keutamaan pada Kursus } \\
\text { Berkepentingan }\end{array}$ & $\begin{array}{l}\text { Sistem dapat memastikan kursus yang mempunyai skor kepentingan } \\
\text { (berdasarkan kepentingan dan tahap kursus) yang tertinggi ditetapkan } \\
\text { pensyarah yang mengajar dahulu diikuti kursus yang berskor rendah. }\end{array}$ \\
\hline $\begin{array}{l}\text { Req 1.2.2: } \\
\text { Penetapan pensyarah Berdasarkan } \\
\text { Bidang }\end{array}$ & $\begin{array}{l}\text { Sistem dapat menetapkan bahawa pensyarah yang ditetapkan } \\
\text { mempunyaibidang yang sama dengan program kursus. }\end{array}$ \\
\hline $\begin{array}{l}\text { Req 1.2.3: } \\
\text { Penetapan pensyarah berdasarkan } \\
\text { pengalaman }\end{array}$ & $\begin{array}{l}\text { Sistem dapat menetapkan bahawa pensyarah yang ditugaskan bagi } \\
\text { kursus berkenaan mempunyai pengalaman mengajar bagi kursus } \\
\text { yang sama, atau berpengalaman mengajar kursus yang berada dalam } \\
\text { kelompok kategori yang sama dengan kursus berkenaan. }\end{array}$ \\
\hline $\begin{array}{l}\text { Req 1.2.4: } \\
\text { Penetapan kumpulan kuliah } \\
\text { menepati beban kredit. }\end{array}$ & $\begin{array}{l}\text { Sistem dapat menugaskan bilangan kumpulan kuliah yang tepat } \\
\text { kepada pensyarah berdasarkan baki beban kredit terkini dan tidak } \\
\text { melebihi beban kredit maksimum pensyarah. }\end{array}$ \\
\hline $\begin{array}{l}\text { Req } 1.3: \text { Penggubalan Jadual } \\
\text { Beban Tugas }\end{array}$ & $\begin{array}{l}\text { Sistem dapat membina jadual beban tugas pengajaran pensyarah bagi } \\
\text { semester terkini berdasarkan kriteria yang ditetapkan. }\end{array}$ \\
\hline $\begin{array}{l}\text { Req 1.3.1: } \\
\text { Penetapan Kelompok Pensyarah } \\
\text { berdasarkan Semester }\end{array}$ & $\begin{array}{l}\text { Sistem dapat memastikan kesemua kursus yang ditugaskan kepada } \\
\text { pensyarah berada pada semester yang sama atau berkaitan. } \\
\text { Contohnya kursus ijazah (A) dan sarjana (M) bagi semester 141, } \\
141 \mathrm{~S}, 142,142 \mathrm{~S} \text { berada dalam kelompok yang sama manakala } \\
\text { diploma (E) } 141,141 \mathrm{~S}, 142 \text { berada dalam kelompok berbeza. }\end{array}$ \\
\hline $\begin{array}{l}\text { Req 1.3.2: } \\
\text { Menyeimbangkan Beban Kredit } \\
\text { Pengajaran per semester }\end{array}$ & $\begin{array}{l}\text { Sistem dapat menyeimbangkan jumlah beban kredit terkini bagi } \\
\text { semua pensyarah mengikut kelompok. Cthnya bagi pensyarah } \\
\text { berjawatan, keseimbangan bergantung pada kredit maksimum iaitu 3- } \\
6 \text { manakala bagi kelompok pensyarah biasa, keseimbangan berada } \\
\text { pada tahap 9-12. Sekiranya majority mempunyai beban kredit } 10 \text {, } \\
\text { maka kesemua pensyarah dalam kelompok yang sama ditugaskan } \\
\text { dengan beban kredit }+-10 \text {. }\end{array}$ \\
\hline $\begin{array}{l}\text { Req 1.4: Memaparkan jadual } \\
\text { beban tugas terkini. }\end{array}$ & $\begin{array}{l}\text { Sistem dapat memaparkan jadual beban tugas lengkap bagi pensyarah } \\
\text { dan kursus yang ditawarkan pada pengguna. }\end{array}$ \\
\hline $\begin{array}{l}\text { Req 1.5: } \\
\text { Pengemaskinian Jadual beban } \\
\text { tugas. }\end{array}$ & $\begin{array}{l}\text { Sistem dapat mengemaskini kesemua maklumat yang terlibat } \\
\text { terhadap perubahan yang dilakukan oleh pengguna pada jadual beban } \\
\text { tugas. }\end{array}$ \\
\hline $\begin{array}{l}\text { Req 2: Pengesyoran Pensyarah } \\
\text { Bagi Tugas Pengurusan Jabatan }\end{array}$ & $\begin{array}{l}\text { Sistem mampu mengesyorkan senarai pensyarah yang layak bagi } \\
\text { tugas pengurusan yang dimasukkan sebagai input. }\end{array}$ \\
\hline $\begin{array}{l}\text { Req 2.1: } \\
\text { Pemilihan pensyarah } \\
\text { Berdasarkan Kriteria bidang } \\
\text { kepakaran }\end{array}$ & $\begin{array}{l}\text { Sistem mampu memilih senarai pensyarah yang mempunyai bidang } \\
\text { kepakaran, SIG, kelayakan akademik, pengalaman penyelidikan dan } \\
\text { kursus yang sama atau dalam kelompok bidang yang sama dengan } \\
\text { tugas yang dinyatakan. }\end{array}$ \\
\hline $\begin{array}{l}\text { Req 2.2: } \\
\text { Pemilihan pensyarah } \\
\text { berdasarkan Kriteria Kredit Beban } \\
\text { Tugas }\end{array}$ & $\begin{array}{l}\text { Sistem mampu menyaring senarai pensyarah yang telah dipilih } \\
\text { berdasarkan beban kredit tugas pengurusan. }\end{array}$ \\
\hline $\begin{array}{l}\text { Req 2.3: Menyusun senarai } \\
\text { cadangan berdasarkan keutamaan }\end{array}$ & $\begin{array}{l}\text { Sistem mampu menyusun kedudukan hasil cadangan berdasarkan } \\
\text { keutamaan atas skor kepakaran/beban tugas }\end{array}$ \\
\hline $\begin{array}{l}\text { Req 2.4: } \\
\text { Memaparkan hasil saranan }\end{array}$ & $\begin{array}{l}\text { Sistem dapat memaparkan senarai cadangan pensyarah yang } \\
\text { berkelayakan bagi tugas yang dinyatakan. }\end{array}$ \\
\hline $\begin{array}{l}\text { Req 2.5: Penetapan pensyarah } \\
\text { bagi tugas pengurusan }\end{array}$ & $\begin{array}{l}\text { Sistem mampu mengemaskini maklumat yang terlibat setelah } \\
\text { pengguna memilih pensyarah yang sesuai bagi tugas yang } \\
\text { dinyatakan. }\end{array}$ \\
\hline
\end{tabular}


Secara kesimpulannya, kajian ini menyelesaikan masalah pengagihan beban tugas secara efisyen dengan mengambil kira elemen penilaian secara telus dan sama rata. Kajian ini juga sedikit sebanyak membantu pensyarah memberi fokus kepada pengembangan bakat mengikut kepakaran bidang masing-masing dalam PdP. Dapatan daripada kajian ini akan digunapakai untuk membangunkan system agihan beban tugas bagi pensyarah untuk memastikan beban tugas yang seimbang dan optimum dapat dihasilkan.

\section{Rujukan}

[1] N. F. Z. Zakaria, Z. Zainal Abidin, M. A. Abdullah Zawawi, and S. N. Shuhada, "Bloodbuddy: a Tracking System for Blood Donor Using GPS", Journal of Engineering, Technology, and Applied Science, vol. 2, no. 2, pp. 86-102, Aug. 2020.

[2] F. D. Putra, J. Riyanto, and A. F. Zulfikar, "Rancang Bangun Sistem Informasi Manajemen Aset pada Universitas Pamulang Berbasis WEB", Journal of Engineering, Technology, and Applied Science, vol. 2, no. 1, pp. 32-50, Apr. 2020.

[3] A. Fatoni, Normalisa, and A. F. Zulfikar, "Merancang Sistem Aplikasi Pendaftaran Kartu Kredit di Bank Panin Kantor Kas Permata Taman Palem", Journal of Engineering, Technology, and Applied Science, vol. 2, no. 1, pp. 59-85, Apr. 2020.

[4] S. Apandi, O. Veza, S. Majid, and P. Pratiwi, "Penentuan Bonus Karyawan dengan Menggunakan Metode Analytic Network Process di PT. Global Harvest Precision Engineering", Journal of Engineering, Technology, and Applied Science, vol. 2, no. 1, pp. 5158, Apr. 2020.

[5] R. Wijayanti and S. Mulyati, "Rancangan Bangun Sistem Informasi Pemantauan Produksi dan Kegiatan antar Divisi", International Journal of Education, Science, Technology, and Engineering, vol. 1, no. 1, pp. 1-14, Dec. 2018.

[6] A. Suganda, R. D. Permatasari, Pratiwi, and I. Y. Panessai, "Sistem Informasi Pemantauan Retribusi Pada Menara Telekomunikasi", International Journal of Education, Science, Technology, and Engineering, vol. 2, no. 2, pp. 97 - 111, Dec. 2019.

[7] Riswandi, Kasim, and M. F. Raharjo, "Evaluasi Kinerja Web Server Apache menggunakan Protokol HTTP2", Journal of Engineering, Technology, and Applied Science, vol. 2, no. 1, pp. 19-31, Apr. 2020.

[8] Yulianti and Normalisa, "Implementasi Arsitektur Client-Server dan Model-View-Controller untuk Membangun Aplikasi Administrasi di SMK Averus Jakarta", Journal of Engineering, Technology, and Applied Science, vol. 2, no. 1, pp. 1-18, Apr. 2020.

[9] A. Herdiyanto and N. Normalisa, "Perancangan Sistem Informasi Akademik SMPN I Tajurhalang", Journal of Engineering, Technology, and Applied Science, vol. 1, no. 1, pp. 1-18, Apr. 2020.

[10] N. H. Hasbullah and N. A. Z. Mohd Noor, "Sistem Temujanji Interaktif Berasaskan WEB", Journal of Engineering, Technology, and Applied Science, vol. 2, no. 3, pp. 110-117, Dec. 2020.

[11] M. Arias, "A Framework for Recommending Resource Allocation based on Process," in Reichert M., Reijers H. (Eds) Business Process Management Workshops. BPM 2015.

[12] B. Pop and F. Boian, "Algorithms for Automating Task Delegation in Project Management," in Proceeding of the 2014 Federated Conference on Computer Science and Information Systems, pp. 1191-1196, 2014.

[13] M. S. Hosain, "Teaching Workload and Performanc: An Empirical Analysis on Some Selected Private Universities of Bangladesh," International Journal of English and Education, vol. 5, no. 7, 2016. doi: 10.2139/ssrn.2810640

[14] Corry. Workload Analysis Teachers in Development Education (Case Studies Teachers in Junior High School District of Pamatang Sidamanik)," International Journal of Academic Research in Business and Social Sciences, vol. 5, no. 1, pp. 399-411, 2015. doi: 10.6007/IJARBSS/ v5-i1/1011

[15] A. S. Ambotang, and N. Bayong, "Hubungan antara beban tugas dan tekanan kerja dengan komitmen guru sekolah rendah," Jurnal Pendidikan Bitara UPSI, vol. 11, pp. 11-21. 